\title{
Recampesinizando los usi civici: Estrategias socioecológicas tradicionales de manejo del territorio entre pastores en Baunei (Cerdeña)
}

\author{
LUCA LiVERANi y DaVId GaLlar HeRnáNDEZ
}

\begin{abstract}
PALABRAS CLAVE: recampesinización, bienes comunes, pastoreo, agroecología.
\end{abstract}

CÓDIGOS JEL: Q01, Q12, Q16, Q18.
7 a industrialización agraria y los nuevos regímenes alimentarios han mo- dificado radicalmente las estructuras socioecológicas agrarias locales y glo- bales, desplazando las estrategias socioecológicas tradicionales de uso y ges- tión de los territorios. En este trabajo, desde una perspectiva agroecológica, se analizan los cambios producidos en la actividad agraria y en el uso de los bienes comunales (usi civici) en el municipio de Baunei (Cerdeña), especialmente en el ámbito de la ganadería.

Mediante una investigación etnográfica, que incluyó observación participante y entrevistas abiertas y semiestructuradas, se ha reconstruido el uso tradicional del territorio y sus estrategias socioecológicas de gestión; los cambios provocados por la modernidad social y agraria; $y$, por último, los nuevos escenarios de recampesinización entre los pastores bauneses para lograr granjas más viables y sustentables. En la investigación se descubren tendencias de recampesinización en los estilos de manejo y en las estrategias socioecológicas tradicionales en los usi civici para tratar de desarrollar el potencial de actualización de dichas formas de manejo y de cooperación social junto con nuevas técnicas agrarias y estructuras organizativas en la construcción de sistemas agroalimentarios y territorios más sustentables. 


\title{
Re-peasantization of Usi Civici: Traditional Socioecological Strategies of Territory Management among Shepherds in Baunei (Sardinia)
}

\section{KEYWORDS: re-peasantization, commons, shepherding, agroecology.}

\author{
JEL CODES: Q01, Q12, Q16, Q18.
}

$\mu \begin{aligned} & \text { grarian industrialization and new food regimes have radically changed so- } \\ & \text { cioecologies of local and global agrarian structures displacing traditional } \\ & \text { socioecological strategies of land use and management. This paper }\end{aligned}$ analyses this transformation from an agroecological perspective by raising the question of how the agrarian activities and the uses of commons have changed in the municipality of Baunei (Sardinia, Italy) with a special focus on livestock farming.

Ethnographic research -through participant observation methods and open and semi-structured in-depth interviews - has enabled to reconstruct the traditional use of land and the strategies of its socioecological management as well as the changes produced by agricultural modernization and modernity at large, and finally, to unveil new perspectives of re-peasantization among Baunei's shepherds to obtain more feasible and sustainable farms. This study highlights tendencies of re-peasantization in land management strategies and the seek for cooperative answers, including an internal reflection on the socioecological meaning of traditional strategies for managing the commons (in usi cicivi) and provides insights to the new potentials of such management and social cooperation practices together with new agricultural techniques and organizational structures in building more sustainable and just food and agricultural systems.

Recepción: 2020-05-18 - Revisión: 2020-09-21 - Aceptación: 2020-10-21

Luca Liverani [orcid.org/0000-0002-7934-4732] es titulado del Máster "Agroecología: un enfoque para la sustentabilidad rural»por la Universidad de Córdoba.C.e.:lucaliver@libero.it

David Gallar Hernández [orcid.org/0000-0003-2273-2555] es investigador del Instituto de Sociología y Estudios Campesinos (ISEC) y profesor del Departamento de Ciencias Sociales de la Universidad de Córdoba. Dirección para correspondencia: Área de Sociología, Campus de Rabanales, N-IV,Km.396, 14014, Córdoba. C.e.:david.gallar@uco.es 


\section{INTRODUCCIÓN}

La sustentabilidad de los sistemas agroalimentarios se ha convertido en una necesidad a la vista de la crisis del modelo agrario industrial, ya reconocida desde la década de 1980 (CMMAD, 1988), pero cuya vigencia es más evidente en la actualidad que nunca (IAASTD, 2009; FAO, 2018a; IPCC, 2019). La búsqueda de formas de agricultura más respetuosas con el medio ambiente y adaptadas a los territorios y a las personas se ha convertido en una responsabilidad científica y social ineludible. Para ello, el aprendizaje del funcionamiento de las formas socioecológicas «tradicionales» (Altieri, 1991; González de Molina, 1991; Toledo \& Barrera, 2008;) o los nuevos contextos de actualización en torno a la agroecología y la soberanía alimentaria (Altieri, Funes-Monzote \& Petersen, 2011; González de Molina, 2013; Giraldo \& Rosset, 2018; Rivera-Ferre, 2018; Rosset \& Altieri, 2018) ofrecen respuestas para la transición hacia nuevos modelos agroalimentarios más sostenibles.

En este sentido, conocer las estrategias tradicionales de gestión campesina de los territorios - pero no desde la bucolización- puede aportar pistas para que, actualizando dichas estrategias históricas a las condiciones actuales, se puedan diseñar procesos y políticas de desarrollo rural sostenible basados en el potencial agroecológico de estos territorios (Guzmán, González de Molina \& Sevilla, 2000; Gallar \& Matarán, 2015). Para ello, en este caso, analizamos el municipio de Baunei, en la isla de Cerdeña, que fue el último lugar de la isla en abandonar algunas de las estrategias básicas de gestión comunitaria del territorio en términos agrarios y que aún mantiene una parte mayoritaria de su término municipal bajo la figura de los usi civici $^{1}$.

El objetivo de este texto es analizar los procesos de recampesinización en Baunei como respuesta a las dinámicas dominantes de industrialización y privatización del sector agrario y del territorio, teniendo en cuenta la influencia de que gran parte del territorio de Baunei esté regulado como usi civici.

El texto se estructura en un primer apartado en el que se abordan los principales debates teóricos vinculados a este caso de estudio. En el segundo apartado se abordan las cuestiones metodológicas. En la siguiente sección, se presentan y discuten los resultados

1. Los usi civici están reconocidos históricamente como el marco legal que regula el uso de la tierra y la define como aquella perteneciente a la colectividad de individuos que histórica y geográficamente viven juntos como una comunidad, y que gestionan el uso del territorio para garantizar el acceso a los recursos naturales (NERVI, 2000, cit. en CACCIARRU, 2010). En la actualidad están recogidos en la Ley Regional 12/1994. 
como respuesta a las preguntas específicas de investigación: 1) cuáles son las estrategias socioecológicas tradicionales de manejo del territorio (vidazzone, emeddare y paberile); 2) cómo se ha dado el proceso de modernización social y agraria que ha implantado la industrialización en el sector agrario con las consecuencias de una mayor intensificación a la vez que ha impulsado la desagrarización del territorio; 3) cuáles son las prácticas de recampesinización y transición agroecológica que algunos pastores están implementando para aumentar sus niveles de autonomía y, cuáles son las estrategias de cooperación tradicionales; 4) y actuales; y 5) su influencia en la construcción de sistemas agroalimentarios y territorios más sustentables. Por último, se presentan las conclusiones.

\section{MARCO TEÓRICO}

La modernización social y agraria han sido procesos que han transformado radicalmente el medio rural en gran parte del mundo. En los países europeos, a partir de los años cincuenta con la revolución verde, el contexto de reconstrucción de posguerra y, posteriormente, la creación de la Comunidad Económica Europea (1957) junto con la Política Agraria Común (1962), se produjo una transformación radical de lo rural, de lo agrario y de los sistemas agroalimentarios, así como su relación con lo urbano, y la modificación de las categorías de lo local y lo global (Sevilla, 2006; Borras, 2009; McMichael, 2016).

A pesar del aumento de los volúmenes de producción, la agricultura y los sistemas agroalimentarios industriales actuales han demostrado, sin embargo, su ineficiencia energética, sus impactos negativos en términos de erosión y degradación de suelos, pérdida de biodiversidad, contaminación de suelos y aguas, deforestación (CMMAD, 1988; IAASTD, 2009), su contribución al cambio climático y a la despoblación rural (IPCC, 2019), y su incapacidad para dar respuesta al derecho a la alimentación adecuada, como uno de los derechos humanos básicos (FAO, 2005; IPES-Food, 2016).

En esta investigación partimos de la propuesta realizada por Ploeg (2010) en torno al proceso de estructuración de la agricultura en tres constelaciones (la agricultura campesina, la agricultura empresarial y la agricultura capitalista a gran escala) y cuáles son las tendencias y dinámicas de cambio social y tecnológico entre ellas: industrialización, desactivación y recampesinización. La industrialización es entendida como una tendencia en la que se da una desconexión total entre la producción y el consumo de alimentos, en la que la producción agrícola pierde el vínculo con las aptitudes de los ecosistemas locales (perdiendo la integridad y organicidad socioecológica) y con un control cada vez mayor de las corporaciones que reordenan la producción, el procesamiento y el consumo de ali- 
mentos, a lo que suman los impactos negativos en términos biofísicos de degradación, sobreexplotación y contaminación. Por otro lado, la desactivación es el proceso por el cual se renuncia a la actividad agrícola material, y también cultural. A su vez, la recampesinización es la tendencia que se orienta a aumentar las cuotas de autonomía socioecológica, manteniendo la lógica de la coproducción ${ }^{2}$ y la intensificación basada en los recursos propios sin deteriorarlos (Ploeg, 2010).

Este marco de distintas constelaciones y distintos escenarios está condicionado por el impacto de la modernización agraria y la revolución verde, cuyo mandato ha sido sustituir o convertir al campesinado y sus estilos de manejo, en empresarios agrícolas con unas formas de producción industriales capaces de adaptarse al mercado y al nuevo régimen alimentario corporativo (Delgado, 2010; Ploeg, 2010; McMichael, 2016). Este nuevo régimen alimentario estaría dominado por lo que Ploeg (2010) define como imperio, entendido como un concepto heurístico para caracterizar las nuevas superestructuras de los mercados globalizantes: «Una gramática o conjunto de reglas contenidas dentro del complejo coherente de conocimiento científico, prácticas de ingeniería, tecnologías de procesos de producción, características de productos, intereses empresariales, ciclos de producción y control, ingeniería financiera, patrones de expansión y maneras de definir problemas, todo esto incrustado en instituciones e infraestructuras» (Ploeg, 2010: 23). Es decir, un modo de ordenación dominante del sistema agroalimentario que alimenta a, y se nutre de, la agricultura empresarial y la agricultura capitalista en gran escala, y que controla cada vez más los procesos de producción, procesamiento, distribución y consumo. Una tendencia que aumenta y sigue absorbiendo explotaciones agrícolas hacia los modos de la agricultura empresarial y su integración en el nuevo régimen alimentario (McMichael, 2016).

Como respuesta a la expansión del poder de este nuevo modo dominante, sin embargo, se pueden reconocer procesos de resistencia en forma de recampesinización, de «retorno de los campesinos» (Pérez-Vitoria, 2010), pero "no como "campesinos de ayer", sino como campesinos del siglo XXI» (Ploeg, 2010: 220). Una tendencia que se expresaría, sobre todo, en un sentido cualitativo y que apunta a cómo una fracción de productores agrícolas modifican sus estilos de manejo para aumentar los grados de campesinidad (Toledo, 1995) en las fincas y en su posición en los sistemas agroalimentarios (Gliessman, 2016; Ploeg, 2016).

2. «La interacción multifacética entre el hombre y la naturaleza y su transformación mutua, es decir, el proceso de producción en el cual la naturaleza se convierte en bienes y servicios para el consumo humano" (Ploeg, 2010: 172). 
Estos procesos de recampesinización son objeto de la investigación agroecológica, que parte de la premisa de la racionalidad ecológica del campesinado y sus manifestaciones particulares en sus propios contextos concretos (Sevilla \& González de Molina, 1993; Toledo, 1995; González de Molina \& Toledo, 2011). La agroecología, como enfoque científico y marco de acción, trata de dar respuesta a la insustentabilidad de los actuales sistemas agroalimentarios y de las prácticas agrarias en finca (Gliessman, 2016, 2018; ONU, 2010). En este sentido, los procesos de transición agroecológica abordan, tanto los cambios hacia manejos ecológico-productivos en finca como las cuestiones individuales-motivacionales, los procesos colectivos y de cooperación social, los marcos estructurales biofísicos y las políticas públicas (Calle, Gallar \& Candón, 2013). A su vez, desde el marco de la agroecología política y su diálogo con la soberanía alimentaria, la agroecología hace hincapié en entender y tratar de transformar las dinámicas de poder en el sistema agroalimentario local y global (ONU, 2009; Holt-Giménez \& Altieri, 2013; Rivera-Ferre, 2018).

Además de todas las propuestas complementarias que desarrolla la literatura citada previamente, este proceso de recampesinización pasaría, según Ploeg, por seis estrategias socioecológicas: 1) diversificación, procesamiento en la finca y circuitos cortos; 2) distanciamiento de los mercados de insumos; 3) la reubicación de agricultura en la naturaleza; 4) el desarrollo de la pluriactividad; 5) el uso o creación de nuevas -o antiguas- formas de cooperación local; y 6) la incorporación de una cultura del trabajo y el conocimiento campesino - el arte de la agricultura (Ploeg, 2016)-, con tecnologías apropiadas y orientadas a aprovechar los recursos propios (Ploeg, 2010: 222), que se traducen en una multitud de respuestas concretas (Ploeg et al., 2019). Es decir, estrategias que apuestan por la autonomía de las fincas, la reducción de gastos, el aprovechamiento y cierre de ciclos dentro de la finca, la orientación a actividades de mayor valor agregado, el uso de innovaciones y tecnología apropiada ${ }^{3}$, y que se convierten, por tanto, en una lucha social frente al régimen agroalimentario.

En este sentido se considera importante atender a cómo se ponen en juego estrategias concretas de recampesinización, cuáles son las lógicas de continuidad con las estrategias campesinas «tradicionales» y cuáles son los nuevos mecanismos de autonomía, autosuficiencia y cooperación social, puesto que aportan elementos de reflexión y acción para el acompañamiento de transiciones agroecológicas en los territorios (Altieri, 1991; Gallar, 2009; López \& Guzmán, 2012; Gallar \& Acosta, 2014; García García \& Moreno, 2018) y el escalamiento de la agroecología (Ferguson et al., 2019; FAO, 2018b). Estos elementos de recampesinización, a su vez, se encuentran condicionados por las formas de acceso a

3. «Tecnologías campesinas, basadas en la habilidad y el conocimiento situado, flexibles y adaptadas a los problemas y recursos locales accesibles» (Ploeg, 2010: 252-254). 
los recursos productivos y al territorio en su conjunto. En el caso de Baunei, la condición de usi civici de gran parte de su territorio alude a las estrategias de uso y gestión de los bienes comunes (Ostrom, 2000) y la importancia de los comunes en la definición y construcción de sistemas agroalimentarios sostenibles y la aplicación de los principios campesinos (Ploeg, 2010) y su vínculo con la propuesta de la soberanía alimentaria y los derechos del campesinado desde una perspectiva de agroecología política (Vara \& Gallar, 2017; Ferrando et al., 2019). En este caso, junto a la figura jurídica de usi civici, los procesos de recampesinización hacen hincapié en la recuperación del sentido, la identidad y las prácticas de comunidad, como herramientas para la gestión colectiva del territorio en la búsqueda de soluciones beneficiosas para todas las partes de acuerdo a las estrategias socioecológicas tradicionales (de manejo y de toma de decisiones y aplicación de sanciones) y nuevas formas de cooperación, tal y como reconoce la quinta estrategia de recampesinización propuesta por Ploeg (2010).

\section{METODOLOGÍA}

Los resultados presentados en este texto son fruto de un proceso de investigación etnográfica (Hammersley \& Atkinson, 2001) en la que se pretendía descubrir las características y conocer las dinámicas en torno a los objetivos de investigación (Rubio \& Varas, 1997). Las técnicas utilizadas han sido las entrevistas abiertas y semiestructuradas, y la observación participante.

Desde una perspectiva estructural de investigación (Ibáñez, 1998) y con un diseño de selección muestral intencional (Coller, 2000), se ha entrevistado a veinticinco personas: actores sociales diferentes entre ellos que actúan e interpretan el territorio comunal y las perspectivas sobre el pastoreo de manera desigual (véase Anexo, Tabla 1). Por un lado, se ha entrevistado a pastores y pastoras ${ }^{4}$ de diversas edades, con diferentes tipos de ganado y grado de dedicación (a título principal o como actividad complementaria), todos ellos miembros de derecho de los usi civici de Baunei. También se ha entrevistado a ancianos y ancianas que se han dedicado a la ganadería toda la vida, para reconstruir la historia agraria del pueblo. Por otro lado, se ha entrevistado a aquellos agentes que trabajan -o han trabajado- en la administración de las tierras comunales y la regulación del pastoreo: el actual teniente de alcalde, personal técnico de la agencia agraria y un exalcalde de Baunei (1975-1985, 1992).

4. En la división sexual del trabajo las mujeres se encargaban más de la agricultura, pero no eran ajenas a las tareas ganaderas. 
La observación participante ha sido realizada entre junio y julio de 2016 en diversas granjas, lugares y contextos del pueblo de Baunei, con diferentes actores, incluyendo a casi todas las personas entrevistadas, así como asistiendo a diferentes eventos relacionados con el sector agrario local (cursos de ganadería ecológica, reuniones abiertas sobre usos de los bienes comunes, etc.).

Especialmente relevante fue el contexto del curso «Transformación de productos lácteos» organizado por la agencia de asistencia técnica regional Laore. En sus dos días de prácticas de campo se dieron múltiples intervenciones en torno a los saberes tradicionales, las presiones actuales del modelo agroindustrial y la necesidad de formas cooperativas. El grupo era de 30 personas, en su mayoría menores de cincuenta años, formado la mitad por mujeres, y más de la mitad eran pastores y pastoras de Baunei. El resto venía de pueblos cercanos, y la mayoría tenía el rebaño en los terrenos comunales. El profesorado estaba compuesto por dos técnicos de la agencia agraria de Cerdeña, Laore, y dos maestros queseros.

Durante el trabajo de campo se tomaron notas que se trasladaron a un diario de campo, se hicieron fotos con una perspectiva etnográfica y se grabaron las entrevistas. El diseño de la investigación estuvo basado en las dimensiones de la agroecología, la información recogida fue ordenada en fichas analíticas según dichas dimensiones, y analizada después con las categorías de las estrategias de recampesinización y de transición agroecológica.

A lo largo de este texto se citarán extractos de las entrevistas, así como anotaciones del diario de campo.

\section{EL TERRITORIO DE BAUNEI}

La provincia de Ogliastra se extiende por 1.854 kilómetros cuadrados, de los cuales dos tercios son montes y el resto, colinas y llanos, prácticamente en su totalidad bajo el estatuto de usi civici.

En la actualidad, los usi civici aún siguen estando reconocidos y protegidos por la Ley Regional 12 del 1994, que incluye una definición ampliada que recoge la función ambiental de tales bienes: «los usi civici, entendidos como derechos de la colectividad sarda de utilizar los bienes inmuebles comunales y privados, respetando los valores ambienta- 
les y los recursos naturales, pertenecen a los ciudadanos residentes en el ayuntamiento en el cual están ubicados los inmuebles al uso $»^{5}$.

El municipio de Baunei, ubicado entre los acantilados de la costa noroeste de la provincia y los montes, tiene un territorio mayoritariamente rocoso que llega a mil metros de altura en el altiplano de Margine. Sus 21.000 hectáreas de superficie están compuestas principalmente por zonas de bosque de encinas y de matorral mediterráneo y áreas accidentadas de rocas cársticas, con escasos recursos hídricos.

TABLA 1

Resumen sobre las diferentes tipologías de uso de suelo en los usi civici

\begin{tabular}{lrr}
\hline Usos del suelo & Total (ha) & \% UDS \\
\hline Territorios modificados artificialmente & 31,92 & 0,17 \\
Territorios agrícolas & 113,01 & 0,60 \\
Territorios boscosos y ambientes seminaturales & $18.610,16$ & 99,00 \\
Cuerpos hídricos & 47,77 & 0,25 \\
Total & $\mathbf{1 8 . 8 0 2 , 8 6}$ & $\mathbf{1 0 0 , 0 0}$ \\
\hline
\end{tabular}

Fuente: elaboración personal a partir de Comune di Baunei (2012: 23).

\section{IMAGEN 1}

\section{Provincia de Ogliastra, Cerdeña}

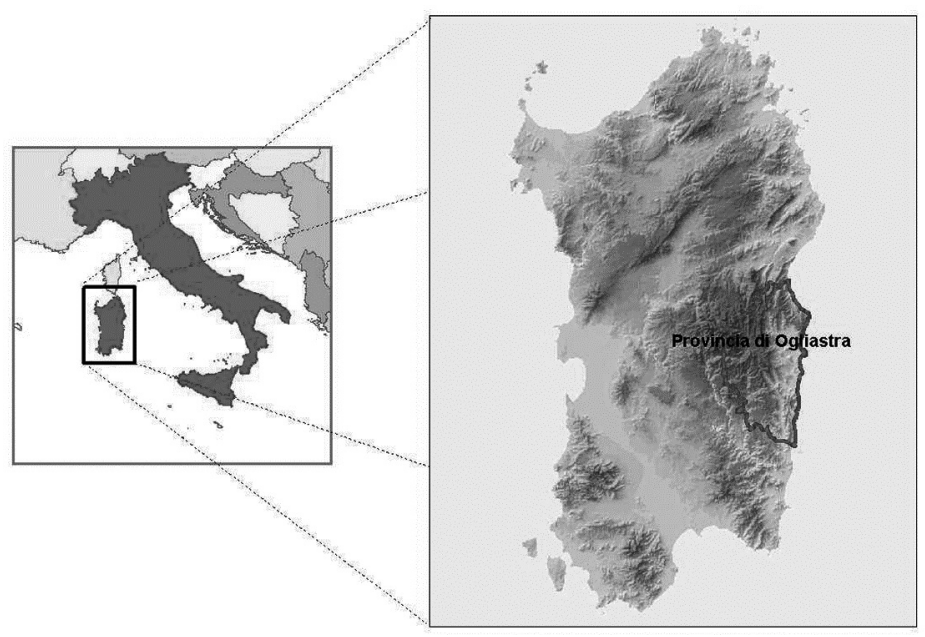

Fuente: Bodini y Cossu (2013: 5).

5. Legge Regionale 14 marzo 1994, n. 12, art. 2 (traducción del autor). 


\section{IMAGEN 2}

Mapa de los usi civici de Baunei
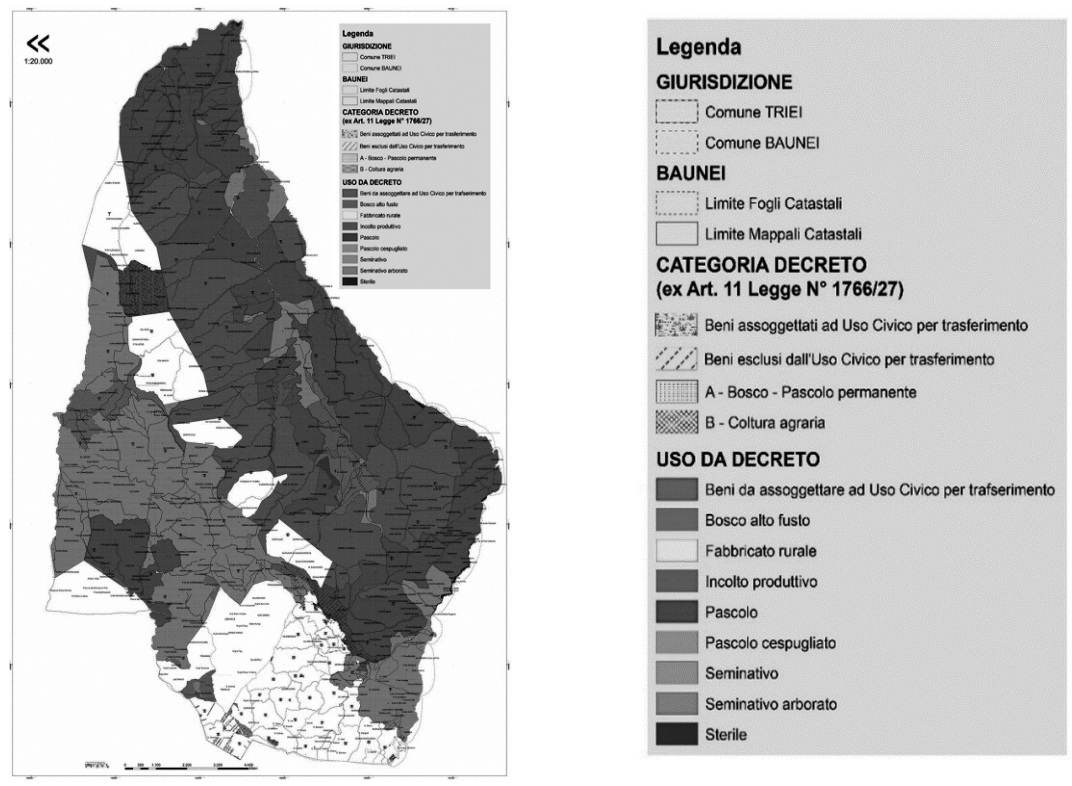

Fuente: Comune di Baunei (2012).

La población de Baunei ha sufrido una elevada disminución en los últimos veinte años: los habitantes de Baunei eran 4.071 en el año 1999, pasaron a los 3.736 en 2011 y han bajado a los 3.564 en 2020 (ISTAT, 2020a). El ápice de población fue en el 1987 (4.287 habitantes) y desde entonces siguió un constante descenso, cuyas causas son atribuidas al movimiento migratorio y a la baja natalidad. Hay un fuerte envejecimiento de la población: en 1951 los mayores de 64 años eran el 8,2\% de la población, en el 2011 suponían el 24,3\% y en el 2020 son el 27,4\%, frente al 22,9\% de la capital de Cerdeña, lo que deja una edad media de 47,7 años (ISTAT, 2020a).

En cuanto a la evolución del sector agrario, podemos adelantar algunos datos de los censos de 1982, 1990 y 2010 (ISTAT, 2020b) cuyo sentido cualitativo se desarrolla a lo largo del texto. Baunei se enmarca en el mismo proceso de desagrarización y abandono de la actividad agraria del conjunto de Italia y de la isla de Cerdeña, en donde se ha dado una reducción del 50\% en el número de explotaciones desde 1982 a 2010. En el caso de Baunei, con datos disponibles de los censos de 2000 y 2010, se aprecia una reducción de un $60 \%$ del número de explotaciones (ISTAT, 2000, 2010). 
En Cerdeña desde 1982 a 2010 el número de explotaciones ganaderas se ha reducido en torno a un $45 \%$, mientras que la dimensión media ha aumentado en un $30 \%$. Del mismo modo, en el sector ganadero en la provincia de Ogliastra ha habido una reducción del $63 \%$ en el número de explotaciones a la vez que un aumento de la dimensión media del $50 \%$ en el caso del bovino y del $72 \%$ en el del caprino (ISTAT, 2020b).

Por su parte, la composición de la cabaña ganadera de Baunei, que ocupa para pastos el $99 \%$ de la superficie agraria utilizada en 2010, ha tendido entre 2000 y 2010 al aumento del ganado bovino (38\%), y a la caída radical del ovino (62\%) y el caprino (52\%); tendencias que son compartidas en signo, aunque no en intensidad, por la evolución de la cabaña provincial desde 1982 a 2010, en la que la ganadería bovina aumentó con más fuerza (63\%), mientras que la disminución de ovino (23\%) y caprino (18\%) fue menor que en Baunei (ISTAT, 2020b).

Como subraya el Plan de Valorización y Recuperación de las Tierras Municipales (Comune di Baunei, 2012), el sector ganadero profesional en Baunei está compuesto, por un lado, por un perfil de explotaciones orientadas a la industrialización, con manejos intensivos, rebaños más grandes (de unas cien vacas o quinientas cabezas en el caso de las cabras) y orientados sobre todo a la venta de leche y, por otro, por un perfil minoritario de pastores con lógicas extensivas (por tamaño de los rebaños, razas, manejos e infraestructuras), mayoritariamente dedicados a la ganadería caprina, con una mayor diversificación y más orientados a la transformación.

Según el diagnóstico del plan de valorización, son muy pocas las empresas agrícolas de dimensiones económicas suficientes para constituir una fuente de ingresos capaz de sustentar a las familias de agricultores, y se asiste a la desagrarización del municipio y la bajísima carga ganadera, y en consecuencia el abandono y matorralización del territorio, y la falta de vigilancia medioambiental. En Baunei la mayor parte de las empresas ganaderas tiene su propia base territorial en los terrenos comunales, utilizados según la reglamentación de los usi civici; mientras que en los terrenos privados se evidencia una fuerte fragmentación, que responde a una ordenación territorial muy frágil e inadecuada (Comune di Baunei, 2012).

Sin embargo, este plan, como diagnóstico y punto de partida para una propuesta de desarrollo endógeno, señala a la ganadería, especialmente de caprino, como una actividad con un alto potencial económico acorde a las condiciones específicas del territorio y a la identidad cultural del lugar. En este sentido, el plan asume la necesidad de profesionalización del sector, facilitando las condiciones mínimas de viabilidad requeridas por el nuevo contexto, a la vez que se aprovechan los recursos locales y genera valor añadido 
a la producción local. Para ello, plantea la opción de la suspensión de los usi civici durante 15 años prorrogables, durante los cuales los usuarios se vuelven de facto propietarios del lote y, por tanto, con la posibilidad de pedir ayudas europeas para proyectos empresariales y edificar estructuras. Así, según el plan, se facilitaría la eliminación de los vínculos administrativos que impiden a las empresas ganaderas modernizarse y seguir con su propia actividad, promoviendo la integración de ingresos con las actividades relacionadas con la transformación, comercialización y valorización de los productos de la ganadería.

\subsection{Una mirada histórica al territorio: Estrategias socioecológicas comunitarias en usi civici}

El territorio de Baunei era una sociedad ocupada en la agricultura y la ganadería hasta que comenzaron los procesos de modernización social y agraria en la década de 1970 (Sapelli \& Scroccu, 2011). La actividad agraria estaba orientada prioritariamente hacia el autoabastecimiento y basada en la explotación comunitaria de la tierra y en algunas parcelas privadas. Como parte de la gestión de los bienes comunes, cada familia del pueblo recibía por parte del consejo comunal un lote de terreno de usi civici, que incluía tierras llanas, de monte y derechos de pastoreo. En ellos se cultivaban cereales en extensivo, tanto para consumo humano como animal; se pastoreaba al ganado, mayoritariamente cabras $\mathrm{y}$ vacas, $\mathrm{y}$ algunos cerdos (hasta la llegada de la peste porcina africana y las restricciones sanitarias desde los años ochenta); y se recolectaba la leña necesaria para las necesidades domésticas. El territorio era gestionado de manera comunitaria mediante prácticas institucionalizadas de gestión cooperativa llamadas: a) vidazzone, que se refiere a los lotes de usi civici concedidos para varios años donde cada familia cultivaba cereales seguidos de uno o dos años de barbecho; b) paberile, al uso como pasto por parte de los pastores de la comunidad de los terrenos en barbecho previamente cultivados en vidazzone; y c) emeddare, referida al intercambio y pastoreo colectivo de rebaños entre varios pastores (Cacciarru, 2010). Estas prácticas comunitarias hacían posible un aprovechamiento agrosilvopastoril integral y extensivo del territorio, y fomentaban la cooperación social para un manejo más eficiente de los recursos naturales y del trabajo familiar.

Estos usi civici tenía como órganos de gestión a las asambleas abiertas y al comité del pueblo, que incluía a los asesores y un número variable de ciudadanos elegidos entre aquellas personas más respetadas y que generaban más confianza por su experiencia en la organización colectiva de la tierra. Los lotes eran distribuidos en las asambleas, mientras que el consejo representaba a la comunidad y vigilaba que las reglas escritas en el reglamento comunal fuesen respetadas, encargándose de resolver las principales fuentes de discusión 
que eran los linderos de los usi civici entre pueblos, si se respetaba o no el reglamento, la coexistencia entre pastores y otros usuarios, o el uso inapropiado de la tierra (Cocco, 2015).

Los distintos aprovechamientos estaban integrados en un ciclo rotatorio y complementario, conformando un mosaico ecológico y productivo en el que se combinaba la actividad agrícola con la ganadera y donde era habitual que la mayoría de los vecinos combinaran ambas actividades. Los terrenos escarpados eran destinados al pastoreo y las tierras llanas al cultivo, tanto en terrenos privados como de usi civici. Esta complementariedad permitía el cierre de ciclos de nutrientes y la optimización de los recursos y del tiempo a través de la cooperación y la ayuda mutua. En definitiva, esto permite caracterizar este tipo de sociedad como una sociedad agraria de metabolismo orgánico (González de Molina \& Toledo, 2011) o, si se prefiere, una economía orgánica avanzada (Wrigley, 2010; Mazoyer \& Roudart, 2016).

En términos ecológicos, paberile favorecía la fertilización de las tierras agrícolas a la vez que era una fuente gratuita de alimento para los animales. Por su parte, emeddare permitía que cada pastor dispusiese de un tiempo para hacer queso o recoger leña, mientras otro pastor cuidaba a sus animales.

«Eran todos pastores-agricultores que compartían entre cuatro un rebaño de unas centenas de cabezas, una semana al mes cada uno, y cuando no estaban en el redil se iban a trabajar en los campos. Volvían desde el redil con el requesón recién hecho, llevado en un recipiente de corcho, su casiddu, con suero y requesón. Los cabritos los dividían en partes iguales. Algunos tenían viña. Entre ellos eran o parientes o amigos» (Baldo).

Como hemos dicho, las dos especies de ganado mayoritarias en Baunei eran vacas y cabras, ambas con un manejo muy similar y habitualmente combinadas entre sí en cada familia. El pastoreo baunese aprovechaba la diversidad de terrenos en su territorio e incluía la trasterminancia para las vacas, en un territorio sin vallas y en el que se aprovechaba las querencias de los animales para manejar sus desplazamientos y el retorno a los rediles.

Este estilo de manejo se basaba en las razas autóctonas (vacas y cabras sardas primitivas), animales muy rústicos, capaces de moverse por el territorio sin perderse o lastimarse, lo que maximizaba el aprovechamiento de los recursos para su alimentación; capaces de regresar a su redil de manera autónoma y de dar una cantidad no muy elevada de leche o carne, pero de gran calidad. Este manejo incluía en los vidazzone la produc- 
ción de un complemento de alimentación para los animales, cultivado por cada familia en la lógica de rotación y barbecho, junto al aprovechamiento a través de paberile de otros terrenos. Así, vemos cómo la adaptación al territorio, la coevolución entre medio ambiente, animal y ser humano, mediante el conocimiento campesino y el «arte de la agricultura» (Ploeg, 2010, 2016), genera en las sociedades campesinas las bases ecológicas de su sustentamiento y reproducibilidad (Vara \& Cuéllar, 2013).

Este manejo del territorio pervivió en Baunei hasta los años setenta-ochenta, siendo el último pueblo de la región en mantener el vidazzone y el emeddare (hasta 1972 el vidazzone y hasta los años ochenta el emeddare), gracias a la relativa autosuficiencia de sus acuerdos socioecológicos, favorecidos por su gran extensión y diversidad de ecosistemas que hacían que los pastores pudiesen practicar una trashumancia de corta distancia dentro de los mismos linderos del territorio comunal.

\subsection{Cambio social y agrario: Desagrarización e intensificación}

Desde los años cincuenta hasta los setenta, la llegada de la modernización social y agraria a la isla y a la región supusieron una transformación radical, además de la modificación de las normas culturales comunitarias y el estatus de la actividad ganadera (Sapelli \& Scroccu, 2011).

El contexto de posguerra y el inicio de la recuperación industrial provocaron un éxodo rural. La papelera Arbatax en los sesenta, la industria petroquímica de la Saras, la construcción de la base militar estadounidense en 1972 y el posterior proyecto estatal de "desarrollo» en clave turística para construir una segunda Costa Smeralda ${ }^{6}$, han sido hitos claves en la desagrarización de la región. Así, la isla de Cerdeña, en dos generaciones, ha visto cambiar profundamente su tejido socioeconómico (Sapelli \& Scroccu, 2011).

En este contexto, el abandono político y económico del sector primario llevó a la desvalorización de la tradición agropastoral; el contraste entre lo arcaico y lo moderno ha determinado la mutación del proceso de producción y el cambio de los hábitos de consumo, debido a la llegada de productos industriales de importación. Después de la generación del boom económico, se ha ampliado el desapego hacia el pastoreo y, ahora, en tiempos de crisis económica, los usi civici pasan a encontrarse entre ser entendidos o como solución colectiva contra la crisis o como bienes parcelables para la riqueza de unos pocos (Cacciarru, 2010).

6. Destino turístico de yates de lujo. 
A su vez, la modernización social vino acompañada de la modernización agraria de la revolución verde. En este período la población rural descendió y cada vez fueron menos los ganaderos y agricultores, sometidos a las nuevas pautas de producción. En este tiempo se produce la transición desde el manejo territorial tradicional a un nuevo modelo en el que los terrenos agrícolas de peor calidad se fueron abandonando por el nuevo contexto socioeconómico, dejando un sector agrícola reducido y con un grupo de ganaderos que se ven impelidos a entrar en la dinámica de la intensificación.

A comienzos de los años ochenta se inició el proceso de transformación de los pastores $^{7}$ en empresarios agrícolas, cuando las explotaciones sustituyeron las vacas y cabras autóctonas por razas más productivas e intensificaron el manejo, dejando de aprovechar los terrenos de los usi civici. Ello significó la estabulación de los animales, el aumento del consumo de piensos (de fuera de la comarca o importados de fuera de la isla), el uso del paquete higiénico-sanitario y la integración vertical y dependiente en la industria cárnica o lechera.

«Samuele, el más joven de los entrevistados (33 años), tiene razas importadas. Él, al estar solo, no tiene tiempo para hacer el queso y entonces aprovecha más la cantidad de la leche que su calidad. Las sanen, maltesas y murcianas son mucho más productivas y tienen un ciclo de ordeño más largo que las sardas, pero en cambio necesitan una cantidad cuatro veces superior de pienso. En definitiva, "más leche, pero más comida, y entonces más gastos"" (Diario de campo, 20/07/2016).

Las explotaciones ganaderas se profesionalizaron, se abandonaron las prácticas comunitarias, como emeddare, y se comenzaron proyectos empresariales en los que las relaciones de producción se limitaron al interior de la unidad familiar y con un nuevo manejo que conllevaba un nuevo marco de inversiones. Un nuevo marco en el que, por indicación de la PAC, se deben redimensionar las explotaciones y adecuarlas a los estándares de seguridad y productividad previstos, lo cual significa remodelar los establos e instalaciones tradicionales y asumir unas inversiones muy altas, que, pese a las ayudas de la PAC, son poco accesibles y con un riesgo muy alto. A todo esto se suma la dificultad del entorno y la necesidad de adecuar el suministro de agua. El incremento de los costes intermedios conduce necesariamente a una estrategia de crecimiento y productivismo continuo para hacerles frente en la que las pequeñas explotaciones tienen poca cabida; es de-

7. En este texto se usará el concepto local de pastor para referirse a los dueños de rebaños, ganaderos tradicionales y nuevos ganaderos, que manejan el ganado con lógicas de extensificación. El término ganadero se referirá a quienes aplican lógicas de manejo intensivo. 
cir, entra de lleno en el proceso de industrialización y sometimiento al dominio del imperio alimentario, señalado por Ploeg (2010).

«Clara con su marido Marco tienen un establo para las vacas cerca de Ardali. Ese establo, comenta Clara, no siendo según los estándares no les permite tener la autorización para vender, por ejemplo, a los restaurantes. La pastora se informó: "para estar según la norma no bastarían las ayudas públicas para hacer un establo adecuado, porque las inversiones que nos requieren son demasiado grandes, nosotros necesitaríamos algo más pequeño"» (Diario de campo, 03/07/2016).

En definitiva, costes de producción muy altos, mientras que los precios de los productos son muy bajos y es muy difícil crear nuevos canales de comercialización que aprovechen un mayor valor añadido. La falta de canales de comercialización para el queso artesano, y la consecuente relativa obligación de vender la leche a los industriales, empujó a la mayoría de los ganaderos a sustituir las rústicas sardas por razas mejoradas, más productivas, pero más delicadas y más demandantes de pienso industrial.

«Es que cada uno vio el dinero, eso es. La selección de las razas se hizo en base a su productividad y no por su rusticidad teniendo en cuenta el pasto, la resistencia a las enfermedades...Y ahora, ¡mira cómo estamos! Los animales seleccionados son delicados y tienen que estar en el establo» (Fiorenza).

En este contexto, la apuesta por el crecimiento y la mayor industrialización es vista por muchos ganaderos como la única opción frente a la «desactivación» (Ploeg, 2010). El alto precio de los insumos y el bajo del producto final exigen al pastor producir más. A ello se suma la imposibilidad de crear un canal de venta del queso y, por tanto, la obligación de vender la leche, lo que convierte a la explotación familiar en dependiente del precio de mercado. De esa manera, el ganadero o ganadera se ve en la obligación de usar cada vez más insumos para alcanzar un nivel mínimo de rentabilidad (de litros o de kilos de carne). Así es como se origina la dependencia de trabajar para una empresa distribuidora, una opción para muchos pastores para probar a incrementar las ganancias.

«Este sería el caso de la propuesta por parte de una empresa a una pareja de ganaderos de vacas, Massimo y Simona. Su caso tiene como punto de partida la necesidad de adecuar sus infraestructuras, lo que para una explotación de doce vacas suponía un coste de en torno a los 250.000 euros. Massimo añade que junto con ese presupuesto "querían hacerme firmar un acuerdo con una empresa del continente que me abastecía de todo el pienso que tenía que dar a los ter- 
neros encerrados. Me proponían hacerlo en intensivo, me planteaban hacer de empleado, atrapado entre el precio del pienso y de la carne que decidían ellos. Y además tendría que usar muchísimos medicamentos para que los animales no enfermen y engorden rápidamente; yo engordo un ternero en ocho meses, ellos lo hacen en tres. Aquí la carne es más buena porque la dieta es diversificada, pero en vez de hacer ganado de diez quintales los hacemos de dos"» (Diario de campo, 16/07/2016).

Sin embargo, a pesar de todo, la eficiencia y el buen manejo no son suficientes y, peor aún, un buen año agrícola tampoco garantiza mejores precios.

«Al ser preguntado sobre quién decide el precio, Sandro contesta: “iPinna! El más grande industrial de la leche que hay en la isla". Interviene otro pastor: "lo fija él y rebaja el precio porque se va a comprar la leche a Rumanía. No puede hacerlo, y aún menos el queso. ¡En cambio lo hace! Menos mal que hace poco, por lo menos una vez lo han pillado en el puerto de Olbia antes que importara desde allí formas de quesos todavía sin marca para marcarlos aquí y ganar más dinero con la marca sarda. ¡Es así! Aprovecha la mano de obra baratísima de Rumanía y nos obliga a nosotros a venderle la leche al precio que dice él"» (Diario de campo, 04/07/2016).

"Este año ha hecho un buen otoño, así que hay un exceso de queso y el precio ha bajado mucho. La leche este año no llega a 80 céntimos de euro, jel año pasado estaba a 1,40 euros! Y esto te fastidia, porque compras alguna cabeza de ganado extra porque el producto se vende bien, y luego al año siguiente son solo costes» (Sandro).

En este contexto, los ganaderos locales no tienen capacidad para consolidar canales de comercialización propios. Las dificultades técnicas, la complejidad administrativa y la enorme inversión para poder legalizar sus infraestructuras para la transformación limitan esta opción. En la actualidad, muchos ganaderos, como complemento a la renta y como práctica tradicional, hacen queso y lo venden de manera informal en círculos de locales y de confianza. Por tanto, a pesar de la fama mundial de los quesos sardos (reconocidos por diversas denominaciones de origen, sobre todo los quesos de oveja, y por el distintivo de productos agroalimentarios tradicionales), la ausencia de canales de comercialización apropiados es un motivo más para depender de la industria. 


\subsection{Dinámicas de recampesinización}

Ante esta situación, de la mano de algunos actores locales y revisando las condiciones históricas de manejo del territorio a través de su uso comunitario y sus estrategias de gestión, parecen atisbarse alternativas reforzadas de un manejo sostenible del territorio que rescate acuerdos socioecológicos válidos en la actualidad para dar respuesta a las dinámicas de productivismo, dependencia e inviabilidad sufridas en el proceso modernizador. Inmersos en un proceso de transición agroecológica, encontramos un cambio de estrategia radical por parte de algunas de las familias de pastores de Baunei. Algunas de ellas han sido entrevistadas en esta investigación y responden a un perfil de hombres y mujeres menores de cincuenta años, en proyectos individuales o en pareja, que aspiran a vivir de la ganadería apostando por un cambio de modelo que les aporte más autonomía. A continuación, se muestran las estrategias de recampesinización y transición agroecológica que coinciden con las propuestas por Ploeg (2010) y otros autores presentados en el marco teórico.

Como respuesta al contexto de industrialización, hay quienes reconsideran su modelo productivo y dan pasos hacia el trabajo con razas autóctonas, menos productivas, pero quizá más rentables. Así, se sustituyen los piensos por el pastoreo, pues estas razas aprovechan el territorio, lo que reduce los costes en alimentación; se aprovechan los recursos de los usi civici, tanto en las zonas de monte para pastoreo como de los llanos para producir algo de alimentación; y se trata de disminuir la dependencia de los canales de comercialización convencionales a través de, por un lado, la transformación en queso artesano y de alta calidad y, por otro, mediante la venta directa, tanto en el caso de la carne como del queso, pensando en afrontar los costes de mejora de las infraestructuras desde posiciones menos dependientes. Es decir, hay una estrategia de reducción de costes, mediante la extensificación del manejo gracias a las razas autóctonas, que viene de la mano de una apuesta por la intensificación en calidad, tanto en carne como en queso, y la búsqueda de valor añadido a través de la transformación y la creación de canales de venta directa. Esto está generando un incipiente retorno a las razas autóctonas, porque son menos "costosas» en términos de insumos y medicamentos.

Esta estrategia de extensificación cuenta además con el potencial de los usi civici como recurso comunitario disponible, que demostró en su momento su viabilidad y sostenibilidad socioecológica, según los acuerdos socioecológicos de la época y sus criterios socioculturales. En la actualidad, tal como recoge el plan de valorización en su diagnóstico sobre el suelo, la morfología y el estado de cobertura vegetal se evidencia: 1) que hay muchas zonas que dejaron de tener uso agrícola desde los años setenta y ahora han sido invadidas por la vegetación, pero a pesar de ello aún muchos de estos terrenos conservan 
potencial agrario y para pasto; y 2) que, a pesar de que el territorio no es muy fértil y tiene una gran prevalencia rocosa, los animales son muy pocos con relación al número que podría soportar el territorio, por lo que las 19.000 hectáreas de territorio comunal están muy lejos de su límite de carga (Comune di Baunei, 2012).

En esta nueva estrategia, la reducción de la producción se compensa, además de con menores costes de producción, con una mayor calidad y rendimiento para el queso, más rico en proteínas y grasas.

«Para hacer la misma cantidad de queso, con la raza sarda necesito cinco litros de leche, con la sanen por lo menos el doble. Además, tampoco es la misma calidad: esos cinco litros de las cabras sardas es leche con mucha grasa, llena de proteínas, muy buena, la leche de las demás razas, ni comparación» (Maurizio).

Ante la situación de dependencia, la alternativa usada por todos los pastores es la búsqueda de canales alternativos, mediante el boca a boca entre parientes, amigos y algún grupo de consumo o venta directa a turistas, que complementen, aunque sea de manera muy minoritaria, sus ingresos.

\subsection{Nuevas formas de cooperación antigua}

Tal y como se planteó en el marco teórico, la cooperación es unos de los elementos claves en los procesos de recampesinización y de transición agroecológica. En este caso, además, se une el hecho de que el territorio está acogido a la figura de usi civici por lo que las estrategias socioecológicas comunitarias de uso y gestión del territorio pueden interpretarse como parte de la «memoria biocultural» del territorio (Toledo \& Barrera, 2008), lo que facilita los acuerdos y consolida los límites sociales de la comunidad.

En términos históricos, los usi civici daban sostén al vidazzone que facilitaba la producción de alimento para complementar la alimentación animal -y familiar- en conjunción con el paberile (por el intercambio de alimentación y fertilización), y el emeddare permitía, mediante la cooperación y la rotación de tareas, la transformación por cada pastor de su queso. Es decir, podemos considerar esas figuras arcaicas como un marco comunitario que favorecía el cierre de flujos de nutrientes y materiales, y canalizaba la cooperación social (González de Molina \& Toledo, 2011). Evidentemente estos acuerdos socioecológicos no se daban sin conflicto, pero existían mecanismos formales (las asambleas y, sobre todo, el comité) e informales de gestión y control social que lo mitigaban y favorecían la cooperación. 
En esta búsqueda de nuevas alternativas, el cambio de manejo, de razas, de orientación, de productos y de canales de comercialización son cuestiones básicas, como plantean, entre otros, las seis estrategias propuestas por Ploeg (2016) y los procesos de transición agroecológica (Calle, Gallar \& Candón, 2013), pero nada de eso es posible sin la existencia de redes de apoyo, de cooperación colectiva y de innovación social que suplan la falta de capacidad financiera de los ganaderos locales.

A primera vista, podría parecer que no existen las bases mínimas de cohesión y confianza colectiva para acometer nada que dé sustento a esta idea general. Tras la irrupción de la modernización todos los espacios comunitarios fueron desmantelados con el éxodo rural y la intensificación agraria. Las asambleas para la gestión de los usi civici se vaciaron de gente y, cada vez más, de contenido. Los pocos ganaderos profesionales se orientaron a la intensificación y el territorio dejó de ser importante como base biofísica más allá de la necesidad de consolidar sus derechos consuetudinarios para lograr la concesión privativa de las instalaciones familiares que se había ido heredando tradicionalmente como parte del modo de manejo ganadero. A su vez, el resto de los habitantes con derechos sobre los usi civici pugnaban a su manera por el intento de privatización para urbanizarlos. Es decir, las estrategias de cohesión y gestión del conflicto en el manejo de los usi civici suponían un marco comunitario que fue desintegrado y ha sido sustituido por la presión productiva y el individualismo, asentados sobre la precariedad y la falta de capitales. La colaboración entre pastores y la buena vecindad han sido abandonadas, aunque aún se coopera cuando se pierde algún animal o en el momento de la esquila (aunque cada vez más se contrata a trabajadores extranjeros). De hecho, las explotaciones se han refugiado en la mano de obra familiar y en la carrera individual en el productivismo a expensas del precio de la leche o de la carne marcado por la industria.

Sin embargo, vemos que en el sector ganadero más inquieto y más joven de Baunei existe cierto consenso sobre la necesidad de encontrar esas fórmulas de apoyo y cooperación. A pesar de la diversidad de situaciones, sin embargo, existe consenso sobre la necesidad de orientar su proyecto productivo hacia la autonomía con respecto a la industria. El rescate adaptado de las estrategias tradicionales podría ser una forma de maximizar recursos y esfuerzos para alcanzar esa autonomía. Es decir, la incorporación de nuevos manejos y nuevas razas requiere igualmente de nuevas respuestas sociales y organizacionales en el modo de uso de los recursos (Ploeg, 2016).

Respecto de vidazzone, como reconoce el plan de valorización, el trabajo colectivo y comunitario de la mejora de los usi civici para transformar en pasto al menos las zonas de cultivo tradicionales que están ahora menos degradadas sería una oportunidad clave para esta extensificación del manejo ganadero, al eliminar el pienso que ahora deben com- 
prar y que supone uno de los principales gastos de las explotaciones. Los usi civici supondrían el marco comunitario de articulación y aval institucional para el aprovechamiento por parte de los pastores de estos terrenos de manera justa y equitativa. Sin embargo, es cierto que el aprovechamiento tradicional se realizaba a costa de un gran esfuerzo social, de mucho trabajo y en un contexto de normalización del esfuerzo físico y la austeridad.

«Sobre la posibilidad de reintroducir los cultivos a vidazzone, la técnica de la agencia agraria Fiorenza coincide con la opinión de Basilio: "Aquí en el llano igual sí, pero en Baunei no, ni lo espero. De lo que me cuenta mi padre era muy duro. ¿Volver a esas condiciones? No... Alguien todavía cultiva el trigo, pero en el llano de Ardali, arriba no. La gente antes se contentaba con poco y era suficiente, además se hacía todo con la azada, sin maquinarias: siega y trilla, todo a mano"» (Diario de campo, 19/06/2016).

En cuanto a emeddare, Pietro y Basilio opinan que es una lástima haber dejado de hacerlo, añadiendo que era una buena división del trabajo y del tiempo.

«Se conseguiría gestionar mejor el rebaño, con menor cansancio. Aquí, con Basilio, menos mal que somos dos, podemos alternarnos si él tiene necesidades de ausentarse y viceversa, si hay imprevistos. En cambio, en el pueblo hay rebaños con un solo pastor, por lo que está prohibido también enfermarse. Tienes que ordeñar sí o sí a la cabra. Tampoco puedes ser sustituido por uno cualquiera, tienes que conocer las cabras una a una; esta se tiene que ordeñar, esta no, conocer los hijos de cada cabra... En otros trabajos puede sustituirte cualquier persona, con el ganado no. Pero sería bueno coordinarse un poco entre varios» (Pietro).

Ante esta necesidad de tiempo y trabajo, la respuesta actual ha sido buscar refugio en la mano de obra familiar. Las empresas que han elegido el cambio de manejo son solo aquellas que pueden contar con ella, puesto que añadir al cambio de orientación y la adecuación de infraestructuras la contratación desde el inicio del proyecto de mano de obra se hace absolutamente inviable. Este cambio de modelo incorpora nuevas tareas, de modo que el trabajo de multiplica. En estos casos acaban siendo las parejas o los familiares más íntimos quienes sostienen esta nueva carga de trabajo.

"A la pregunta de si Simona trabaja con él, Massimo subraya: "sí, mucho. Ella se encarga de la administración de la empresa; cuando por ejemplo voy a cargar el heno, ella conduce el tractor y yo coloco los fardos; algunas veces también 
mi padre me ayuda. Todos ayudan, también mi niña. El hombre solo no vale nada". Simona, a su vez, comenta: "aparte de ayudar con el tractor, también me encargo de hacer el queso, pero más que nada me dedico a hacer el pistoccu ${ }^{8} \mathrm{y}$ a cuidar de los dos niños, mientras que Massimo y mi suegro están dando vueltas vigilando las vacas, llevando el forraje, o trabajando los campos para producir el pienso"” (Diario de campo, 15/07/2016).

Mientras tanto, quienes no cuentan con ningún otro apoyo estable en la explotación solo pueden mantenerse en la espiral de mecanización y productivismo dependiendo de los precios de la industria.

«Solo no llegas a hacer nada. Yo estando solo no llego a hacer el queso. Ordeño, llevo la leche, llevo las cabras al pasto, vuelves tarde. Cada día así. Es difícil, mejor ser dos. Pero no es fácil encontrar a alguien con quien llevarte bien» (Samuele).

En estas explotaciones familiares que han iniciado la transición hacia formas más autónomas se está dando de manera concomitante una nueva división sexual del trabajo, incorporándose las mujeres como responsables de la transformación de la leche en queso, tarea que hasta ahora había sido típicamente masculina. Sin embargo, esto no parece haber supuesto una incorporación igual del hombre en las tareas de cuidados.

Por todo ello, podemos atisbar que los usi civici y sus estrategias de gestión comunitaria pueden ser interpretados como un marco sociocultural que pueda ayudar a mejorar la situación actual.

«Samuele y Massimo comparten la misma opinión: "los usi civici es un sistema óptimo, que siempre ha existido en Baunei. Si alguien lo quería arruinar se arruinaba. Si está todavía así intacto es porque la gente del pueblo lo ha manejado bien"» (Massimo) (Diario de campo, 20/07/2016).

«La pastora Viviana aclara que "hay lugar para todos, el ayuntamiento te da las hectáreas, hay un registro de los ganados y pagas tanto por cabeza, porque el terreno no es tuyo, es de todos.Y justamente pagas cada año un alquiler, algo casi simbólico. Sobre los usi civici nada de malo que decir porque nos están dando de comer y los estamos usando para llevar adelante a la familia") (Diario de campo, 12/07/2016).

8. Un tipo de pan de pastor en forma de láminas crujientes y que se utiliza en múltiples recetas tradicionales. 
Estos usi civici, frente a las dinámica de privatización o usurpación para usos no agrarios, son reconocidos como un recurso colectivo por parte de los ganaderos profesionales mayores y jóvenes que avalan el uso consuetudinario de la herencia en el acceso y uso de los terrenos de usi civici como una manera de proteger las inversiones realizadas en su mejora, pero con la condición ineludible de que el uso debe ser igualmente agrario: es decir, se reconoce el derecho de traspaso siempre que quien herede mantenga también la actividad profesional ganadera.

«Sí [me parece justo que pueda heredar el redil]: si mi hijo quiere quedarse con las cabras, sí. Si tiene otra idea para su vida, no» (Pietro).

\subsection{Reagrarización cultural y nuevas formas de cooperación}

Estos nuevos escenarios abren también otras nuevas vías de acción que van más allá de las estrategias tradicionales. Muestra de ello es que entre todas las entrevistadas se expresa el valor de la posibilidad de constituir una cooperativa en la cual varias familias -o personas- pudiesen compartir los gastos y el canal de venta para salir de la dependencia de la industria.

Esta no es una idea totalmente nueva, ya que en los años noventa, como recuerda Pietro, se intentó constituir una asociación de pastores y una quesería: «intentaron hacer una asociación, pero no salió bien. Querían hacer una quesería, pero al final no se llevaron bien. Han pasado muchos años. Falta organización». Una propuesta, la de la quesería cooperativa, que según este pastor, aunque no cuajó, era y sigue siendo buena en la actualidad: «claro que es buena. Pero igual en Baunei no la hicieron por una cuestión de mentalidad, también miedo tal vez, no tenemos mucho el ánimo empresarial. Prefieren hacer las ocho horas... En Baunei tenemos esa cosa de no arriesgarnos».

Quizá el contexto de modernización, de cambio sociocultural, de promesas y presiones de la modernización agraria y la precariedad de los ganaderos hiciesen fracasar aquella iniciativa, pero sí parece que en la actualidad con un contexto y una trayectoria recorrida por estos ganaderos y con la incorporación de nuevos protagonistas más jóvenes, las necesidades de autonomía y los «dolores» con respecto a la modernización social y agraria, pueden ser un nuevo punto de partida para la creación de una quesería cooperativa. Tal y como se pudo apreciar durante la observación participante en el curso de transformación quesera para productores de la comarca organizado por la agencia Laore, se hizo explícita entre las asistentes la necesidad de organización y cooperación, y la predisposición a generar una quesería cooperativa y una red de pastores y pastoras que se 
aprovechara de las sagre (fiestas de la cabra) y del turismo para poder generar ingresos, además de consolidar el acceso al mercado local.

Así pues, este nuevo contexto sociocultural de la mano de nuevos pastores jóvenes, incluye como factor clave una ligera tendencia a retomar los trabajos de campo, a redescubrir las actividades ligadas al territorio. Ante la crisis de los empleos y con la posibilidad de pedir subvenciones europeas para jóvenes agricultores, los hijos e hijas de Baunei, que ahora tienen entre treinta y cuarenta años, redescubren la ganadería como cultura, como forma de vida y como proyecto productivo.

«A lo largo de estas dos generaciones se perdió mucho de la sabiduría sobre cómo hacer el queso. [...] Todos tenían parientes pastores, pero muchos padres preferían que los hijos no continuaran en el sector primario, así que esta tradición se ha ido perdiendo» (Serafino).

«En los cursos anteriores, en algunos pueblos los pastores no sabían qué hacer si les ponían delante una caldera de leche para hacer el queso. Estos eran los de treinta años que nunca les habían enseñado a hacer queso, los que lo sabían hacer eran los de más de cincuenta; también en los pueblos del interior solo algunos que tenían el padre pastor y que les enseñó cómo hacerlo» (Serafino).

«Clara, junto con su marido, Marco, producen queso desde hace diez años. Marco hizo de guía turístico durante quince años, y ahora están muy contentos los dos de haber vuelto al pastoreo, y Clara al comentar el curso de transformación quesera en el que se realizó observación participante, evidencia el proceso de "redescubrimiento": "[en el curso] se aprenden muchas cosas nuevas, encuentras y compartes opiniones con otras personas. A mí me enseñó mi padre"》 (Diario de campo, 06/07/2016).

Reagrarización cultural, redescubrimiento de la actividad ganadera, recampesinización, que oscila entre la tradición y la innovación: tanto en el manejo de los animales o de los cultivos como en las recetas del queso ${ }^{9}$ o las formas cooperación.

Ante la necesidad de cooperación también se plantea cómo generar vínculos con los consumidores. Algo reconocido por los pastores y las pastoras que están en este proceso

9. En este sentido, podemos ver el caso del suero injerto para abordar la cuestión de la continua adaptación de la tradición, una innovación que no usaban Mauro y su padre. Las pruebas que está haciendo Viviana contribuyen a solucionar los problemas del proceso tradicional del queso. 
de recampesinización, quienes apuntan las dificultades provocadas por los cambios de hábitos de consumo y los nuevos gustos de los consumidores. La pauta tradicional de consumo era que «cada familia compraba unos veinte kilos de queso [al año], ahora coge solo un cuarto", y se compraba entre vecinos. Sin embargo, los cambios de las últimas décadas han conducido a que las familias, por diversos motivos, compren menos queso artesano: en las tiendas y supermercados encuentran quesos con precios más baratos, con disponibilidad permanente, lo que les evita tener que guardarlos en sus propias casas, con sabores más estandarizados y sin el «riesgo» de que salgan deteriorados.

"Uno de los pastores apunta que las personas se han acostumbrado a comprar en la tienda "solo un poquito para la nevera, además son quesos en crema envasados, cosas de afuera".Y Sandro puntualiza que la gente se ha acostumbrado a un producto siempre igual, en cambio el queso artesano varía según la temporada " $y$ cuando sale un queso no muy bueno los clientes te hacen quedar mal con todo el pueblo. Solo quien ha invertido en maquinarias puede vender un producto estándar. Usan las bolsitas para añadir los sabores, en cambio de manera casera cada queso tiene su sabor: hoy las cabras han pastoreado allá arriba, mañana en el pasto abajo, y hierba y plantas son diferentes. Contrariamente a los quesos industriales donde le agregan sobres para sabores y utilizando leche pasteurizada. Ya con la leche cruda los gustos son totalmente diferentes”》 (Diario de campo, 16/07/2016).

Por último, es necesario apuntar las expectativas percibidas en torno al papel del turismo por los actores locales de la estrategia de cambio socioeconómico, tanto desde las productoras como desde el ámbito institucional, recogido también en el plan de valorización como un complemento económico y un refuerzo identitario y cultural. A partir de pensar en la opción de la quesería cooperativa aparece el sector del turismo, y tanto unos como otros se atreven a imaginar un escenario que retroalimentaría las dinámicas de apoyo mutuo, confianza y cooperación. Todos los entrevistados han expresado su opinión positiva acerca de la quesería cooperativa y su vínculo con el turismo: la fama de la cabra autóctona y la calidad de sus quesos, sumada al flujo anual de turistas interesados en las bellezas paisajísticas, podrían generar bastante demanda, lo que se traduciría en trabajo e ingresos, si bien esta relación aún es demasiado débil y se requiere mayor organización y articulación colectiva entre los pastores y mayor apoyo desde las políticas públicas para acceder a este mercado. 


\section{CONCLUSIONES}

En este caso de estudio se aprecian claramente las estrategias de recampesinización y las distintas dinámicas de transición agroecológica presentadas en el marco teórico. A lo largo del texto, en las prácticas de algunos jóvenes pastores de Baunei se aprecian claramente las estrategias de búsqueda de autonomía frente a las presiones del imperio alimentario y sus lógicas de productivismo, mecanización, industrialización e integración en sus gramáticas, instituciones e infraestructuras (Ploeg, 2010).

Estos jóvenes pastores de Baunei están siendo conscientes de las presiones del imperio alimentario y han apostado por las siguientes estrategias de recampesinización (Ploeg, 2010): cambiar a un modelo productivo que reubique la agricultura en la naturaleza con el uso de razas autóctonas y la reactivación del cultivo para alimento animal (estrategia 3); distanciarse de los mercados de insumos (estrategia 2); recuperar el conocimiento tradicional y crear una nueva cultura campesina del trabajo para generar una identidad como pastores que les haga redescubrir la relación con el territorio y los animales (estrategia 6); apostar por la independencia de la industria agraria orientándose a la producción de queso y carne para la venta directa en mercados locales (estrategia 1), incluyendo las expectativas de vincularse al sector turístico y manteniendo la economía familiar diversificada, siempre que sea posible (estrategia 4); y aprovechar la oportunidad de reactivar antiguas formas de cooperación social y generar nuevas (estrategia 5).

Estas prácticas de recampesinización y de búsqueda de autonomía se apoyan en el marco normativo de uso y gestión del territorio en forma de usi civici, y aportan a su memoria biocultural (Toledo \& Barrera, 2008) estrategias socioecológicas de gestión. Los usi civici sirven como elemento social de cohesión y generación de identidad colectiva, facilitando un marco de gestión comunitaria al que recurrir, rescatando, revitalizando o resignificando las formas tradicionales de cooperación y manejo (asambleas, comités, vidazzone, emeddare y paberile), y también como marco en el que construir nuevos escenarios y formas de articulación y cooperación territorial (cooperativa, quesería colectiva, mercados locales, turismo).

Así, junto al cambio de manejo y la transición agroecológica en finca se dan nuevas formas de articulación cooperativa que aprovechan, tanto el marco institucional de los usi civici como las motivaciones individuales y colectivas vinculadas a la reagrarización cultural, a la recampesinización material y productiva y también cultural (Calle, Gallar \& Candón, 2013). 
Las instituciones comunales del campesinado sardo adquieren una nueva significación en este contexto de crisis de la agricultura y la ganadería industriales, y ofrecen pistas para construir procesos de desarrollo rural sostenible. Las estrategias de vidazzone, paberile y emeddare en usi civici no son la solución, pero sí pueden aportar respuestas y aprendizajes para aumentar la sostenibilidad local junto a las nuevas dinámicas de recampesinización: el aprovechamiento de la rotación de parcelas y cultivos y el cierre de ciclos biofísicos (vidazzone y paberile), el trabajo conjunto y el reparto de tareas en estrategias de diversificación productiva (emeddare), y el acceso a bienes comunes (usi civici) con instituciones (asambleas y consejos) de gestión de los usos y conflictos socioecológicos del territorio son elementos clave para la transición agroecológica. De este análisis sociohistórico del territorio se pueden extraer aprendizajes que aportan respuestas a la viabilidad de la actividad agraria de la zona desde una perspectiva agroecológica y de desarrollo rural sostenible.

Desde esta perspectiva podemos recuperar el planteamiento sobre la necesidad de basarse «en el descubrimiento, la sistematización, análisis y potenciación de los elementos de resistencia locales frente al proceso de modernización, para, a través de ellos, diseñar, de forma participativa, estrategias de desarrollo definidas a partir de la propia identidad local de etnoagroecosistema concreto» (Sevilla, 2006: 211). Evidentemente, no tiene sentido pensar en reimplantar las prácticas tradicionales en el contexto actual, sino que se trata de extraer aprendizajes mediante la investigación agroecológica y acompañar procesos locales de desarrollo endógeno, como los que pretende impulsar el propio municipio a través del plan de valorización, como los propios pastores locales más jóvenes y más inquietos, y que pudiesen ampararse bajo iniciativas de protección como las de protección del patrimonio agrario (Castillo et al., 2013).

\section{AGRADECIMIENTOS}

A todos los pastores y pastoras de Baunei y a todas aquellas personas que aportaron sus conocimientos y su tiempo para permitir este trabajo. Agradecemos las minuciosas aportaciones de quienes han realizado la revisión por parte de Historia Agraria de las distintas versiones del texto, a los editores su profesionalidad y amabilidad, y a Manuel González de Molina sus útiles sugerencias.

\section{REFERENCIAS}

Altieri, M. A. (1991). ¿Por qué estudiar la agricultura tradicional? Agroecología y Desarrollo, 1 (1), 16-24. 
Altieri, M., Funes-Monzote, F. \& Petersen, P. (2011). Agroecologically Efficient Agricultural Systems for Smallholder Farmers: Contributions to Food Sovereignty. Agronomy for Sustainable Development, (32), 1-13. https://ink.springer.com/article/10.1007/s13593-011-0065-6

Bodini, A., Cossu, Q.A. (2013). Analisi della piovosità in Ogliastra (Sardegna, Italia) nel periodo 1951-1999. Milano: Consiglio Nazionale delle Ricerche, Istituto di Matematica Applicata e Tecnologie Informatiche.

Borras, S. (2009). Agrarian Change and Peasant Studies: Changes, Continuities and Challenges. Fournal of Peasant Studies, 36 (1), 5-31.

Cacciarru, A. (2010). Where we come from: Common Problems and Local Solutions to the Land Tenure Issue in Rural Sardinia, Italy. Carolina Digital Repository, https://cdr.lib.unc.edu/concern/parent/sb397886g/file_sets/q811kk18d

Calle, A., Gallar, D. \& Candón, J. (2013). Agroecología política: La transición social hacia sistemas agroalimentarios sustentables. Revista de economía crítica, (16), 244277. http://revistaeconomiacritica.org/node/680

CASTILlo, J. et al. (2013). Carta de Baeza sobre patrimonio agrario. En J. CASTILlo (Dir.), Carta de Baeza sobre Patrimonio Agrario (pp. 27-45). Sevilla: Universidad Internacional de Andalucía. https://www.unia.es/explorar-catalogo/item/carta-de-baeza

Comisión Mundial del Medio Ambiente y del Desarrollo (CMMAD) (1988). Nuestro futuro común. Madrid: Alianza.

Cocco, C. (2015). Cundannaus a bius: Creencia y representación de los conflictos en una sociedad agro-pastoril de Cerdeña. Barcelona: Universitat de Barcelona. http://diposit.ub.edu/dspace/handle/2445/106378

Coller, X. (2000). Estudio de casos. Madrid: CIS.

COMUNE DI BAUNEI (2012). Piano di valorizzazione e recupero delle terre civiche. Cerdeña: Regione autonoma della Sardegna, assessorato dell'agricoluta e riforma agropastorale, Argea Sardegna. Progettista: Dr. Agr. Enzo Ibba. Relazione generale 11-2012.

Delgado, M. (2010). El sistema agroalimentario globalizado: Imperios alimentarios y degradación social y ecológica. Revista de economía crítica, (10), 32-61. http://www.revistaeconomiacritica.org/node/523

Organización de las Naciones Unidas para la Alimentación y la Agricultura (FAO) (2005). Directrices voluntarias en apoyo de la realización progresiva del derecho a una alimentación adecuada en el contexto de la seguridad alimentaria nacional. Roma: FAO. http://www.fao.org/3/y7937s/y7937s.pdf

Organización de las Naciones Unidas para la Alimentación y la AgRicultura (FAO) (2018a). Transition towards Sustainable Food and Agriculture: An Analysis of FAO's 2018-2019 Work Plan. www.fao.org/3/I9007EN/19007en.pdf

ORganización de las Naciones Unidas para la Alimentación y la AgRicultura (FAO) (2018b). Catalysing Dialogue and Cooperation to scale up Agroecology: Out- 
comes of the FAO Regional Seminars on Agroecology https://ec.europa.eu/ knowledge4policy/publication/catalysing-dialogue-cooperation-scale-agroecologyoutcomes-fao-regional-seminars_en.

Ferguson, B. G., Aldasoro, M., Giraldo, O., Mier, M., Giménez Cacho, T., MoraLes, H. \& Rosset, P. (2019). Special Issue Editorial: What do we mean by Agroecological Scaling? Agroecology and Sustainable Food Systems, 43 (7-8), 722-723.

Ferrando, T., Claeys, P., Diesner, D., Vivero, J. L. \& Woods, D. (2019). Commons and Commoning for a Just and Agroecological Transition: How to Decolonize and Decommodify our Food Systems. En C. Tornaghi \& M. DehaEne (Eds.), Resourcing an Agroecological Urbanism: Political, Transformational and Territorial Dimensions (pp. 61-84). New York: Routledge. https://www.researchgate.net/publication/ 337935069_Commons_and_Commoning_for_a_Just_Agroecological_Transition_The _Importance_of_Decolonising_and_Decommodifying_our_Food_Systems

GALLAR, D. (2009). La recuperación del conocimiento tradicional campesino como herramienta del desarrollo rural sustentable. Documentación social, (155), 133-151.

GallaR, D. \& Acosta, R. (2014). La resignificación campesina de la ruralidad: La Universidad Rural Paulo Freire. Revista de Dialectología y Tradiciones Populares, (69), 285304. http://dra.revistas.csic.es/index.php/dra/article/view/453

GALLAR, D. \& MATARÁN, A. (2015). La construcción social de la ruralidad: Coevolución, sustentabilidad y patrimonialización. En J. CASTILlo \& C. MARTínez YÁÑEZ (2015), El Patrimonio Agrario: La construcción cultural del territorio a través de la actividad agraria (pp. 72-89). Sevilla: Universidad Internacional de Andalucía. https://www.unia.es/explorar-catalogo/item/patrimonio-agrario

García García, M. \& Moreno, M. (2018). De huertas y rebaños: Reflexiones históricas y ecológicas sobre el papel de la ganadería en al-Ándalus y aportaciones arqueozoológicas para su estudio. Historia Agraria, (76), 7-48. https://doi.org/10.26882/ histagrar.076e $01 \mathrm{~g}$

GiRAldo, O. F. \& Rosset, P. (2018). Agroecology as a Territory in Dispute: Between Institutionality and Social Movements. The fournal of Peasant Studies, 45 (3), 545-564.

Gliessman, S. (2016). Transforming Food Systems with Agroecology. Agroecology and Sustainable Food Systems, 40 (3), 187-189.

Gliessman, S. (2018). Defining Agroecology. Agroecology and Sustainable Food Systems, 42 (6), 599-600.

GonZÁlez de Molina, M. (1991). Agroecología: Bases teóricas para una historia agraria alternativa. Historia Agraria, (2), 49-78. http://www.historiaagraria.com/es/ numeros/manuel-gonzalez-de-molina-agroecologia-bases-teoricas-para-una-historiaagraria-alternativa 
GonZÁlez de Molina, M. (2013). Agroecology and Politics: How To Get Sustainability? About the Necessity for a Political Agroecology. Agroecology and Sustainable Food Systems, 37 (1), 45-59.

GonZÁlez de Molina, M. \& Toledo, V. (2011). Metabolismos, naturaleza e historia: Hacia una teoria de las transformaciones socioecológicas. Barcelona: Icaria.

GuZMÁn, G., GonZÁlez de Molina, M. \& SEvilla, E. (2000). Introducción a la agroecología como desarrollo rural sostenible. Madrid: MundiPrensa.

Hammersley, M. \& Atkinson, P. (2001). Etnografía: Métodos de investigación. Barcelona: Paidós.

Holt-Giménez, E. \& Altieri, M. A. (2013). Agroecology, Food Sovereignty, and the New Green Revolution. Agroecology and Sustainable Food Systems, 37 (1), 90-102.

International AsSessment of Agricultural Knowledge, SCIENCE AND TeCHnoLOGY FOR DEVELOPMENT (IAASTD) (2009). Agriculture at a Crossroads: Global Report. Washington, DC: Island Press. http://www.fao.org/familyfarming/detail/en/c/286358/

IbáÑEZ, J. (1998). Del algoritmo al sujeto: Perspectivas de la investigación social. Madrid: Siglo XXI.

Intergovernmental Panel on Climate Change (IPCC) (2019). Climate Change and Land: Special Report. https://www.ipcc.ch/srccl/

International Panel of Experts on Sustainable Food Systems (IPES-Food) (2016). From Uniformity to Diversity: A Paradigm Shift from Industrial Agriculture to Diversified Agroecological Systems. www.ipes-food.org

IstiTUto NAZIONALE Di STATistica (ISTAT) (2000). $5^{\circ}$ Censimento agricoltura 2000. https://www.istat.it/it/censimenti-permanenti/censimenti-precedenti/agricoltura/agricoltura-2000-

Istituto NAZionale di STATistica (ISTAT) (2010). $6^{\circ}$ Censimento agricoltura 2010. https://www.istat.it/it/censimenti-permanenti/censimenti-precedenti/agricoltura/agricoltura-2010

Istituto NAZIONALE Di STATISTICA (ISTAT) (2020a). Censimento permanente popolazione e abitazioni. https://www.istat.it/it/censimenti-permanenti/popolazione-e-abitazioni Istituto Nazionale di Statistica (ISTAT) (2020b). Agricoltura. https://www.istat.it/it/agricoltura

López, D. \& GuZMÁn, G. (2012). «Si la tierra tiene sazón... »: El conocimiento tradicional campesino como movilizador de procesos de transición agroecológica. Agroecología, 7 (2), 7-20.

Mazoyer, M. \& Roudart, L. (2016). Historia de las agriculturas del mundo. Oviedo: KRK.

MCMichael, P. (2016). Regímenes alimentarios y cuestiones agrarias. Barcelona: Icaria. 
ORganización DE LAS NACIONES UnidAs (ONU) (2009). Informe del Relator Especial sobre el derecho a la alimentación, A/HRC/13/33-Agroindustria. http://daccessddsny.un.org/doc/

ORganizaCión DE LAS NACIONES UNIDAS (ONU) (2010). Informe del Relator Especial sobre el derecho a la alimentación, A/HRC/16/49-Agroecología. http://daccessddsny.un.org/doc/

Ostrom, E. (2000). El gobierno de los bienes comunes. La evolución de las instituciones de acción colectiva. México: UNAM-FCE.

Ploeg, J. D. van DER (2010). Nuevos campesinos: Campesinos e imperios alimentarios. Barcelona: Icaria.

PloEg, J. D. vAN DER (2016). El campesinado y el arte de la agricultura: Un manifiesto chayanoviano. Barcelona: Icaria.

Ploeg, J. D. van DeR et al. (2019). The Economic Potential of Agroecology: Empirical Evidence from Europe. Fournal of Rural Studies, (71), 41-61.

Rivera-Ferre, M. G. (2018). The Resignification Process of Agroecology: Competing Narratives from Governments, Civil Society and Intergovernmental Organizations. Agroecology and Sustainable Food Systems, 42 (6), 666-685.

Rosset, P. \& Altieri, M. A. (2018). Agroecología: ciencia y política. Barcelona: Icaria.

Rubio, M. J. \& VARAS, J. (1997). El análisis de la realidad en la intervención social: Métodos y técnicas de investigación. Madrid: CCS.

SAPELli, G. \& SCROCCU, G. (2011). L'occasione mancata: Lo sviluppo incompiuto della industrializzazione sarda. Roma: CUEC.

SEvilla, E. (2006). De la sociología rural a la agroecología. Barcelona: Icaria.

Sevilla, E. \& GonzÁlez DE Molina, M. (Eds.) (1993). Ecología, campesinado e historia. Madrid: La Piqueta.

Toledo,V. (1995). La apropiación campesina de la naturaleza: Un análisis etnoecológico. México, DF: Universidad Autónoma Metropolitana.

Toledo, V. \& BARrerA, N. (2008). La memoria biocultural: La importancia ecológica de las sabidurías tradicionales. Barcelona: Icaria.

VARA, I. \& CUÉLlAR, M. (2013). Biodiversidad cultivada: Una cuestión de coevolución y transdisciplinariedad, Ecosistemas, 22 (1), 5-9. https://www.revistaecosistemas.net/ index.php/ecosistemas/article/view/758

VARA, I. \& GALLAR, D. (2017). El papel de los manejos comunales en la construcción de procesos hacia la soberanía alimentaria. En N. Alonso, Rebeldías en común: Sobre comunales, nuevos comunes y economías cooperativas (pp. 183-194). Madrid: Libros en Acción.

Wrigley, E. A. (2010). Energy and the English Industrial Revolution. Cambridge: Cambridge University Press. 


\section{ANEXO}

TABLA 1

Personas entrevistadas (en orden cronológico)

\begin{tabular}{|c|c|c|c|c|c|}
\hline Persona E & Edad (aprox.) & Sexo & Actividad profesional & Lugar de entrevista & Fecha \\
\hline Riccardo & 30 & Hombre & $\begin{array}{l}\text { Producción vitícola, agrícola } \\
\text { y cría de cerdos }\end{array}$ & Su granja & 24/06/2016 \\
\hline Rosanna & 65 & Mujer & Jubilada, agricultora & Su casa & $25 / 06 / 2016$ \\
\hline Basilio & 70 & Hombre & Jubilado, pastor & Su redil & $\begin{array}{r}\text { De 06/07/2016 } \\
\text { a 09/07/2016 }\end{array}$ \\
\hline Pietro & 50 & Hombre & Albañil, pastor & Su redil & $\begin{array}{r}\text { De 06/07/2016 } \\
\text { a 09/07/2016 }\end{array}$ \\
\hline Baldo & 80 & Hombre & Jubilado, agricultor & Su granja & $10 / 07 / 2016$ \\
\hline Elda & 65 & Mujer & Jubilada, agricultora & Su granja & $10 / 07 / 2016$ \\
\hline Viviana & 50 & Mujer & Pastora, limpiadora de casas & Su redil & $\begin{array}{r}\text { De 10/07/2016 } \\
\text { a 13/07/2016 }\end{array}$ \\
\hline Mauro & 50 & Hombre & Pastor & Su redil & $\begin{array}{r}\text { De 10/07/2016 } \\
\text { a 13/07/2016 }\end{array}$ \\
\hline Samuele & 33 & Hombre & Pastor & Su redil & $\begin{array}{r}\text { De } 19 / 07 / 2016 \\
\text { a 21/07/2016 }\end{array}$ \\
\hline Massimo & 40 & Hombre & Pastor & Montes de Margine & $\begin{array}{r}\text { De } 14 / 07 / 2016 \\
\text { a 16/07/2016 }\end{array}$ \\
\hline Simona & 40 & Mujer & Pastora & Su casa & $14 / 07 / 2016$ \\
\hline Gavino & 50 & Hombre & Teniente de alcalde & Ayuntamiento & $27 / 06 / 2016$ \\
\hline Pantaleo & 65 & Hombre & Jubilado, exalcalde, profesor, historiador & Su casa & $18 / 07 / 2016$ \\
\hline Fiorenza & 50 & Mujer & Técnica de agencia agraria & Su despacho & $19 / 07 / 2016$ \\
\hline Vittorio & 50 & Hombre & Técnico de agencia agraria & Su despacho & $19 / 07 / 2016$ \\
\hline Biagio & 50 & Hombre & Técnico y profesor de agencia agraria & $\begin{array}{l}\text { En el redil (curso de } \\
\text { transformación quesera) }\end{array}$ & $\begin{array}{r}29 / 06 / 2016 \\
\text { y } 04 / 07 / 2016\end{array}$ \\
\hline Serafino & 50 & Hombre & Técnico y profesor de agencia agraria & $\begin{array}{l}\text { En el redil (curso de } \\
\text { transformación quesera) }\end{array}$ & $\begin{array}{r}29 / 06 / 2016 \\
\text { y } 04 / 07 / 2016\end{array}$ \\
\hline Giuseppina & 40 & Mujer & Pastora & $\begin{array}{l}\text { En el redil (curso de } \\
\text { transformación quesera) }\end{array}$ & $\begin{array}{r}29 / 06 / 2016 \\
\text { y } 04 / 07 / 2016\end{array}$ \\
\hline Sandro & 40 & Hombre & Pastor (Urzulei) & $\begin{array}{l}\text { En el redil (curso de } \\
\text { transformación quesera) }\end{array}$ & $\begin{array}{r}29 / 06 / 2016 \\
\text { y } 04 / 07 / 2016\end{array}$ \\
\hline Maurizio & 40 & Hombre & Pastor (Cardedu) & $\begin{array}{l}\text { En el redil (curso de } \\
\text { transformación quesera) }\end{array}$ & $\begin{array}{r}29 / 06 / 2016 \\
\text { y } 04 / 07 / 2016\end{array}$ \\
\hline Marco & 40 & Hombre & Pastor & En el redil (curso de & $29 / 06 / 2016$ \\
\hline
\end{tabular}




\begin{tabular}{|c|c|c|c|c|c|}
\hline Persona & Edad (aprox.) & Sexo & Actividad profesional & Lugar de entrevista & Fecha \\
\hline & & & & transformación quesera) & y 04/07/2016 \\
\hline \multirow[t]{2}{*}{ Clara } & 40 & Mujer & Pastora & En el redil (curso de & $29 / 06 / 2016$ \\
\hline & & & & transformación quesera) & y 04/07/2016 \\
\hline \multirow[t]{2}{*}{ Florinda } & 40 & Mujer & Pastora & En el redil (curso de & $29 / 06 / 2016$ \\
\hline & & & & transformación quesera) & y 04/07/2016 \\
\hline \multirow[t]{2}{*}{ Dario } & 50 & Hombre & Licenciado en agronomía y agricultor & En el redil (curso de & $29 / 06 / 2016$ \\
\hline & & & & transformación quesera) & y 04/07/2016 \\
\hline \multirow[t]{2}{*}{ Carlo } & 30 & Hombre & Licenciado en agronomía y agricultor & En el redil (curso de & 29/06/2016 \\
\hline & & & & transformación quesera) & y 04/07/2016 \\
\hline
\end{tabular}

